\title{
Conflito de Competências na Fiscalização de Alimentos de Origem Animal no Brasil: Uma Análise da Legislação em Vigor no Brasil
}

\author{
RESPONSIBILITY CONFLICT TO ANIMAL FOOD \\ PRODUCTS INSPECTION: ANALYSIS \\ ABOUT BRAZILIAN LAW
}

Patrícia Borges de Carvalho ${ }^{(*)}$

\section{RESUMO}

A fiscalização e a inspeção de alimentos de origem animal no Brasil vem, há anos, enfrentando controvérsias e indefinições acerca de um possível conflito de competências entre os Ministérios da Saúde e da Agricultura. Foi realizado levantamento e análise das principais normas em vigor relativas ao assunto frente a alguns princípios do Direito Constitucional e Administrativo. A avaliação detalhada da legislação em vigor no país referente ao assunto, bem como seu confronto com o texto e com os princípios constitucionais, possibilitou a conclusão pela confirmação da existência de tal conflito. A pesquisa jurisprudencial não revelou haver grande número de questionamentos judiciais referentes ao assunto. Apesar disso, a avaliação jurídico-legal divulgou fortes indicativos de que a atribuição do controle dos alimentos em geral, inclusive os de origem animal, compete ao Sistema Único de Saúde e foram apresentadas propostas para correção das possíveis irregularidades e para a adequação da estrutura administrativa federal às normas legais e constitucionais.

\section{Descritores}

Vigilância Sanitária; Inspeção de alimento; Agricultura.

(*) Médica Veterinária, Especialista em Saúde Coletiva e em Direito Sanitário. Mestranda em Nutrição Humana na UnB e Inspetora de Vigilância Sanitária do DF. End. QE 30 CJ P casa 22 Guará II - Brasilia, DF. e-mail: pcborges@terra.com.br — Recebido em 7.8.03. Aprovado em 10.10.03. 


\section{ABSTRACT}

Animal food products inspection in Brazil has been facing controversy and uncertainty related to the responsibility conflict between Health and Agriculture Ministries. A research of the main laws in force related to the subject was made considering the principles of Constitutional and Administrative Law. Detailed evaluation of the laws in force as well as its comparison to the Constitution of the country resulted in the confirmation about the existing conflict. Jurisprudential research did not present many judicial questioning about the subject. Nevertheless, legal evaluation revealed strong indicatives that the attribution of food control, including animal food products, is a responsibility of the Sistema Único de Saúde - SUS (Brazilian Health System). Some suggestions to correct possible irregularities and to adequate federal administrative structure to the laws are presented.

\section{Keywords}

Sanitary Vigilance; food; responsibility; inspection; Agriculture.

\section{INTRODUÇÃO}

A vigilância sanitária tem tido sua importância reconhecida nas últimas duas décadas, tanto pelo ponto de vista do Poder Público quanto pela população em geral. Tal fato pode ser facilmente demonstrado por ela ter merecido constar do texto da Constituição Federal de $1988^{(1)}$. O novo texto

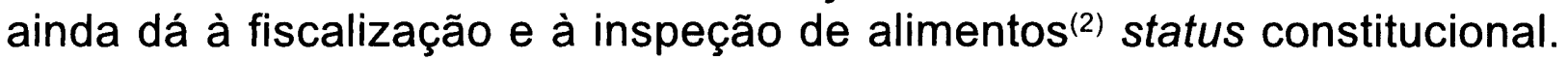

A vigilância sanitária, entretanto, no que tange ao controle de alimentos, principalmente os de origem animal, como carnes, ovos, leite e mel, tem enfrentado dificuldades relativas a um suposto conflito de competência existente entre o Sistema Único de Saúde - SUS - e os órgãos públicos ligados ao setor de agricultura brasileiro.

O artigo que se segue decorreu da necessidade de esclarecer dúvidas geradas pelas controvérsias e indefinição existentes a respeito de quem seria o agente - ou órgão - competente para fiscalizar e inspecionar estabelecimentos produtores de alimentos de origem animal, bem como para realizar o controle de tais produtos no comércio atacadista e varejista.

Tal questão, após o advento da Constituição de 1988, era pacífica, pois a fiscalização estava confiada à União, que o fazia por meio do Ministério da Agricultura, tutelado pela Lei n. 1.283, de 1950. Mas, princi-

(1) O artigo 200, inciso II, da Constituição Federal dá, como competência do Sistema Único de Saúde, "executar as ações de vigilância sanitária ...".

(2) Inciso VI do artigo 200 da Constituição Federal. 
palmente a partir da nova ordem constitucional, que promoveu a instituição do Sistema Único de Saúde e maior autonomia aos Estados e Municípios, a questão referente aos alimentos de origem animal vem passando por muitas discussões, em razão de uma aparente incompatibilidade entre normas constitucionais e leis anteriores - hoje recepcionadas"(3) "na prática" - e com leis posteriores à sua promulgação. Em outras palavras, leis que não deveriam ter sido recepcionadas pela Constituição continuam sendo aplicadas pelas instituições públicas.

Alguns dos principais problemas que podem ser gerados pela indefinição resultante desse conflito são:

- A duplicidade de fiscalização para fins sanitários em um mesmo estabelecimento;

- Alimentos de mesma natureza sendo registrados em dois ministérios diferentes (sucos, bebidas e alimentos à base de mel, por exemplo);

- Estabelecimentos que impedem a entrada de inspetores da saúde por já sofrerem fiscalização pela agricultura, inclusive prejudicando a realização de ações voltadas à vigilância à saúde do trabalhador, competência esta do Sistema Único de Saúde;

- Ausência de controle social no planejamento das ações e na fiscalização da aplicação dos recursos, um dos princípios do Sistema Único de Saúde;

- Omissão por parte de setores das Administrações Públicas estaduais e municipais que, por desconhecerem os limites de atuação de cada órgão, omitem-se em assumir sua parcela de responsabilidade, principalmente no combate à clandestinidade;

- Conflitos e embates políticos entre órgãos fiscalizadores dos diversos níveis de governo e até mesmo entre os de mesmo governo;

- Cadastramento de laboratórios diferentes para emissão de laudos oficiais de análise fiscal de produtos alimentícios. Na saúde, os Laboratórios Centrais de Saúde Pública - LACENS são os responsáveis pelos laudos oficiais e, na agricultura, além dos laboratórios do próprio Ministério, laboratórios particulares são por ele credenciados para a realização das análises e emissão dos laudos.

- Duplicidade de normatização sobre processos de produção, de registro, de rotulagem e de transporte de alimentos, ou seja, existência em vigor de Portarias e atos do Ministério da Agricultura tratando de assuntos similares aos tratados por Resoluções da Agência Nacional de Vigilância Sanitária.

(3) O termo "recepcionada" informa a situação em que uma lei anterior à nova ordem constitucional, quando compatível com seus termos, continua em vigência no ordenamento jurídico. 
Um exemplo que muito bem ilustra a duplicidade de normatização é a comparação entre a Portaria n. 326/97 do Ministério da Saúde com a Portaria n. $368 / 97$, expedida praticamente um mês depois da primeira. Elas tratam respectivamente de "Aprovar o Regulamento Técnico: Condições Higiênico-Sanitárias e de Boas Práticas de Fabricação para Estabelecimentos Produtores/ Industrializadores de Alimentos" (art. 1ㅇ) e de "Aprovar o Regulamento Técnico sobre as Condições Higiênico-Sanitárias e de Boas Práticas de Fabricação para Estabelecimentos Elaboradores/Industrializadores de Alimentos" (art. 10). Podese observar que o que muda no assunto tratado pelas duas normas é somente a palavra "Produtores" que, na norma da Agricultura, passa a ser "Elaboradores".

Curiosamente, comparando os conceitos de Produção de Alimentos (item 3.15 da Portaria n. 326/97) e de Elaboração de Alimentos (item 2.3 da Portaria n. 368/97), os quais são respectivamente "o conjunto de todas as operações e processos efetuados para obtenção de um alimento acabado" e "o conjunto de todas as operações e processos praticados para a obtenção de um alimento terminado", é fácil concluir que possuem o mesmo significado.

O mais interessante ainda a ser observado é que as duas normas fazem referência à Resolução GMC n. 80/96, ou seja, tratam do mesmo assunto, possuem os mesmos conceitos e foram criadas com a mesma finalidade, ou seja, a de compatibilizar as normas nacionais com as internacionais do MERCOSUL.

A duplicidade de normatização confunde o consumidor, o setor regulado e os próprios agentes públicos federais, estaduais e municipais.

Este trabalho visa contribuir para a resolução desta desarmonia, para que o sistema jurídico-normativo e as estruturas organizacionais dos serviços de inspeção encontrem sua coerência e compatibilidade com os mandamentos constitucionais vigentes. Para isso, foi realizado estudo das legislações conflitantes e sua avaliação segundo a doutrina jurídica dominante e os princípios do Direito Administrativo e Constitucional.

O estudo tem por objetivo principal avaliar o ordenamento jurídico brasileiro no que diz respeito à competência legal para realizar a fiscalização dos alimentos de origem animal, incluindo a dos processos de abate dos animais e da industrialização dos produtos.

Para alcançar tal objetivo, foi realizado um levantamento da legislação federal referente ao assunto, tanto anterior à promulgação da Constituição de 1988 - para identificar os dispositivos por ela recepcionados(4) - quanto posterior - para identificar possíveis conflitos com o novo texto, ou seja, a existência de supostas inconstitucionalidades ${ }^{(5)}$.

(4) Dispositivos recepcionados são aqueles vigentes antes de entrar em vigor a nova ordem constitucional e que, não estando em conflito com o novo texto, continuam a gerar efeitos jurídicos. Segundo Jorge Miranda, todas as normas jurídicas, legais e regulamentares, precisam ser relidas e reinterpretadas à luz da nova Constituição e, quando contrárias, não são recepcionadas e são tacitamente revogadas. Ou seja, se a nova interpretação não for possível, e se a antiga não for acolhida, tem-se a revogação da lei. Importante lembrar que, segundo a melhor doutrina, não se pode falar em inconstitucionalidade de lei anterior à Constituição, sendo "revogação" o termo tecnicamente correto.

(5) Uma norma pode ser material ou formalmente inconstitucional. A primeira quando o assunto tratado está em conflito com o texto constitucional e a segunda quando não foi respeitado o rito 
Boa parte da legislação relativa à competência para fiscalização e inspeção de produtos de origem animal, teve sua publicação anterior à promulgação da Constituição de 1988, e deve ser cuidadosamente avaliada para que sejam identificados os seus pontos com ela conflitantes e, portanto, revogados.

Foi também realizada uma busca jurisprudencial relativa a possíveis julgados, dos Tribunais Superiores e Tribunais Regionais Federais, relacionados ao assunto nos últimos cinco anos nas regiões onde se localizam os principais centros produtores dos alimentos em questão.

Diante dos problemas e indefinições existentes, urge encontrar respostas a questões como: à luz do ordenamento jurídico brasileiro são os órgãos da agricultura competentes para realizar a fiscalização/inspeção dos alimentos de origem animal? Se existe competência dos setores ligados à Agricultura para a fiscalização de produtos alimentícios de origem animal, onde ela começa e onde termina? A partir de que processos o Ministério da Saúde inicia suas atribuições? Se a Constituição Federal tirou de fato a competência de atuação dos órgãos da Agricultura, por que até hoje eles atuam na prática contrariando os dispositivos legais e mesmo constitucionais?

Além de poupar o desgaste entre os poderes do Estado, a solução do conflito de normas e, conseqüentemente, de competências de atuação dos órgãos e de seus agentes na fiscalização e inspeção de estabelecimentos e produtos de origem animal traria indubitavelmente uma maior harmonia e eficiência à Administração Pública, pois não haveria uma sobreposição de ações, nem tampouco intempéries entre saúde e agricultura, que passariam a ser complementares e não concorrentes.

processual exigido pela Constituição para a elaboração da lei até sua sanção e publicação. Em se tratando de leis e normas publicadas após a vigência da nova Carta Magna brasileira, há que se falar em inconstitucionalidade - dita material - quando estas normas tratarem de matérias conflitantes com o texto ou com principios da Constituição Federal. O princípio da Supremacia da Constituição a coloca no ponto mais alto da ordem jurídica do país, impondo que todas as situações normativas se acomodem sob os seus ditames e sejam com ela compativeis e harmônicos para que seja garantida a hierarquia vertical do ordenamento juridico. Segundo o mestre José Afonso da Silva, "Nossa Constituição é rígida. Em conseqüência, é a lei fundamental e suprema do Estado brasileiro. Toda a autoridade só nela encontra fundamento e só ela confere poderes e competências governamentais. Nem o governo federal, nem os governos dos Estados, nem os dos Municipios ou do Distrito Federal são soberanos, porque todos são limitados, expressa ou implicitamente, pelas normas positivas daquela lei fundamental. Exercem suas atribuições nos termos nela estabelecidos". "..., todas as normas que integram a ordenação juridica nacional só serão válidas se se conformarem com as normas da Constituição Federal". A inconstitucionalidade de uma lei pode ser questionada basicamente por duas vias: a de ação direta, perante o Supremo Tribunal Federal, e a via concreta, também chamada por Celso Bastos de difusa ou via de defesa. A ação direta de inconstitucionalidade, apelidada de ADIn, pode ser impetrada somente pelos ativamente legitimados constantes do artigo 103 da Constituição Federal, cujo detalhamento não é relevante para este estudo. Importante se torna frisar que uma lei, estando em desconformidade com a Constituição Federal, poderá e deverá ser questionada e tornada inválida por meio de ADIn. 


\section{A FISCALIZAÇÃO E A INSPEÇÃO DE ALIMENTOS DE ORIGEM ANIMAL — O QUE DIZEM AS NORMAS}

Os órgãos da Agricultura, antes do novo texto constitucional e ainda hoje, se pautam na Lei n. 1.283, de 18 de dezembro de 1950, para tutelar sua atribuição. A lei, que trata da inspeção industrial e sanitária dos produtos de origem animal, estabelece a obrigatoriedade da prévia fiscalização de todos os produtos de origem animal, ou seja, das carnes, do leite, dos pescados, dos ovos e do mel, e ainda de seus derivados.

"Art. 1ํ É estabelecida a obrigatoriedade de prévia fiscalização, sob o ponto de vista industrial e sanitário, de todos os produtos de origem animal, comestiveis e não comestíveis, sejam ou não adicionados de produtos vegetais, preparados, transformados manipulados, recebidos acondicionados, depositados e em trânsito."

\section{Em seu artigo $3^{\circ}$, dispõe que a fiscalização far-se-á:}

"nos estabelecimentos industriais especializados e nas propriedades rurais e com instalações adequadas para a matança de animais e o seu preparo ou industrialização, sob qualquer forma para o consumo."

Além das indústrias, incluem-se no seu âmbito de atuação, segundo a mesma lei, os entrepostos ${ }^{(6)}$, as propriedades rurais e ainda as casas atacadistas e varejistas de alimentos ${ }^{(7)}$.

$O$ regulamento da Lei $n$. 1.283/50 define os estabelecimentos sob controle dos órgãos da agricultura:

"Art. 8 ํㅡㄹ Entende-se por estabelecimento de produtos de origem animal, para efeito do presente Regulamento, qualquer instalação ou local nos quais são abatidos ou industrializados animais produtores de carnes, bem como onde são recebidos, manipulados, elaborados, transformados, preparados, conservados, armazenados, depositados, acondicionados, embalados e rotulados com finalida-

(6) Entrepostos são locais de recebimento, armazenamento, fracionamento, acondicionamento e distribuição de produtos, sem criação ou abate de animais. Não se confundem com casas atacadistas, pois estas não dispõem de qualquer manipulação ou fracionamento, somente distribuição e comércio por atacado.

(7) Lei n. 1.283 de 1950. Art. $3^{\circ} \mathrm{A}$ fiscalização, de que trata esta Lei, far-se-á: a) nos estabelecimentos industriais especializados e nas propriedades rurais e com instalações adequadas para a matança de animais e o seu preparo ou industrialização, sob qualquer forma para o consumo; b) nos entrepostos de recebimento e distribuição do pescado e nas fábricas que o industrializem; c) nas usinas de beneficiamento do leite, nas fábricas de laticínios, nos postos de recebimento, refrigeração e desnatagem do leite ou de recebimento, refrigeração e manipulação dos seus derivados e nos respectivos entrepostos; d) nos entrepostos de ovos e nas fábricas de produtos derivados; e) nos entrepostos que, de modo geral, recebem, manipulam, armazenam, conservam ou acondicionam produtos de origem animal; f) nas propriedades rurais; g) nas casas atacadistas e nos estabelecimentos varejistas; 
de industrial ou comercial, a carne e seus derivados, a caça e seus derivados, o ovo e seus derivados, o mel e a cera de abelhas e seus derivados e produtos utilizados em sua industrialização."

A Lei n. 1.283/50, em seu art. $4^{\circ}$, depois de alterado pela Lei $n$. 7.889 , de 23 de novembro de 1989 , elenca os órgãos competentes para fiscalização e aplicação da lei e de seu regulamento, sendo:

a) o Ministério da Agricultura;

b) as Secretarias ou Departamento de Agricultura dos Estados, dos Territórios e do Distrito Federal, nos estabelecimentos, que façam apenas comércio municipal ou intermunicipal e nos casos da alínea $f$ do artigo mencionado em tudo que não esteja subordinado ao Ministério da Agricultura;

c) os órgãos de saúde pública dos Estados, dos Territórios e do Distrito Federal, nos estabelecimentos de que trata a alínea $g$ do mesmo art. 3‥ (Lei n. 1.283/50)

A alínea $g$ citada refere-se aos estabelecimentos comerciais atacadistas e varejistas de produtos de origem animal. Em outras palavras, segundo este diploma jurídico, o Sistema Único de Saúde somente tem atuação sobre os estabelecimentos comerciais sejam atacadistas ou varejistas, deixando para a Agricultura as indústrias e os entrepostos de produtos.

O Regimento Interno do Departamento de Inspeção de Produtos de Origem Animal - DIPOA, hoje em vigor, enumera suas atribuições.

"Art. 67 Ao Departamento de Produtos de Origem Animal compete:

I - elaborar as diretrizes de ação governamental para inspeção de produtos e derivados de origem animal, com vistas a subsidiar a reformulação da política agrícola;

II - programar e promover a execução das atividades de inspeção sanitária e industrial de produtos de origem animal; (grifo nosso)

III - promover auditorias técnico-fiscal e operacional das atividades pertinentes a sua área de competência."

Subordinado diretamente ao DIPOA, há o setor responsável pela inspeção e pelos registros dos produtos e dos estabelecimentos, a Divisão de Operações Industriais. O Regimento Interno dispõe:

"À Divisão de Operações Industriais compete:

I - coordenar e exercer a orientação técnica das atividades de:

a) inspeção ante mortem e post mortem de animais de açougue;

b) inspeção industrial, sanitária e tecnológica dos produtos e derivados de origem animal;

c) inspeção dos estabelecimentos que industrializem, beneficiem, manipulem, acondicionem e armazenem produtos e derivados de origem animal; 
III - aprovar a concessão, renovação e cancelamento de registros de produtos e resíduos de valor econômico, destinados ou não à alimentação humana, inclusive os adicionados de produtos vegetais, bem como o registro dos estabelecimentos que os industrializem, beneficiem e armazenem"; (grifo nosso)

Ainda diz a Lei:

"Art. 6ํㅡ Expressamente proibida em todo o território nacional, para os fins desta lei, a duplicidade de fiscalização industrial e sanitária em qualquer estabelecimento industrial ou entreposto de produtos de origem animal, que será exercida por um único órgão."

Este artigo proíbe que um mesmo estabelecimento seja fiscalizado, para os mesmos fins - ou seja, fins sanitários -, por dois ou mais órgãos do Estado. Exigência esta coerente de forma a preservar os estabelecimento da dúvida de saber a quem obedecer.

Hélio Dias (2002), em parecer elaborado em 1976 sobre o mesmo assunto, tema deste trabalho, acredita que a introdução deste dispositivo teve a única intenção de coibir a atuação dos órgãos de saúde pública junto aos estabelecimentos de origem animal. Ele afirma em seu texto:

"O objetivo da disposição é transparente: como seria inevitável e fatal a fiscalização sanitária - e esse termo usado, quer dizer, quando procedida pelos órgãos da saúde pública, foi preciso proibir, expressamente, a duplicidade desta atividade a repartição estranha ao Ministério da Agricultura. Sabendo-se que os órgãos públicos são criados para uma determinada finalidade, não há porque a norma proibir a duplicidade de fiscalização."

Mesma finalidade - a de proibir a duplicidade de fiscalização - tem a Lei n. 8.080/90 quando, em seu art. $7^{\circ}$, estabelece, como um dos princípios das ações e serviços públicos de saúde, a "organização dos serviços de modo a evitar duplicidade de meios para fins idênticos". Deste modo, a duplicidade de órgãos fiscalizadores com um mesmo intuito carrega mais de uma ilegalidade.

Mais um argumento então surge para reforçar a necessidade urgente de se corrigir e se definir limites claros de competências para a vigilância sanitária de alimentos.

O parágrafo único do art. 6º da Lei n. $1.283 / 50$ reforça o caput do artigo tentando demonstrar que o estabelecimento já registrado pelo órgão federal de agricultura é dispensado de qualquer outra fiscalização sanitária estadual ou municipal, mas tem gerado óbices aos órgãos de saúde pública, que têm eventualmente sido proibidos de adentrar aos estabelecimentos sob controle da agricultura.

"Parágrafo único. A concessão de fiscalização do Ministério da Agricultura, isenta o estabelecimento industrial ou entreposto de fiscalização estadual ou municipal." 
Em 1969, foi editado o Decreto-lei n. 986 que, em seu art. 3o, estabeleceu que "todo alimento somente será exposto ao consumo ou entregue à venda depois de registrado no órgão competente do Ministério da Saúde". Considerando que lei mais nova revoga lei anterior no que the é contrária, desde a edição do Decreto-lei, já se poderia ter deixado de aplicar o dispositivo da Lei n. 1.283/50 que dá competência ao Ministério da Agricultura. Pois, não se pode colocar que a inspeção da indústria seja feita por um Ministério - como o determinado pela Lei n. 1.283/50 - e o registro dos produtos seja expedido por órgão de outro Ministério, pois o registro de produtos pressupõe análise tanto da documentação relativa à empresa e aos profissionais, quanto dos processos e das tecnologias de produção, das instalações físicas e da rotulagem, bem como das análises laboratoriais de controle de qualidade.

A atuação dos órgãos da agricultura desde então, na fiscalização e no registro dos produtos e dos estabelecimentos industriais, tem supostamente ignorado o princípio da legalidade, segundo o qual, lembra Meirelles, "a eficácia de toda a atividade administrativa está condicionada ao atendimento da lei".

Costa e Rozenfeld (2000) ainda lembram que, antes da edição do Decreto-Lei n. 986/69, vigorava o CBA - Código Brasileiro de Alimentos - instituido pelo Decreto-lei n. 209/67, que continha normas de defesa e proteção da saúde, desde a produção dos alimentos até o seu consumo. As autoras ressaltam que este código também não fazia qualquer menção à atribuição da agricultura no controle dos alimentos, mas, apesar disto, não revogou expressamente sua competência.

Outro dispositivo legal que vale a pena ser citado e que reforça ainda mais a atribuição dos órgãos da saúde para realizar o controle sanitário dos alimentos no Brasil é a Lei n. 6.437, de 20 de agosto de 1977, a qual "configura infrações à legislação sanitária federal, estabelece as sanções respectivas, e dá outras providências". Nela, lê-se:

“Art. 1As infrações à legislação sanitária federal, ressalvadas as previstas expressamente em normas especiais, são as configuradas na presente Lei.

Art. 10. São infrações sanitárias:

1 - construir, instalar ou fazer funcionar, em qualquer parte do território nacional, laboratórios de produção de medicamentos, drogas, insumos, cosméticos, produtos de higiene, dietéticos, correlatos, ou quaisquer outros estabelecimentos que fabriquem alimentos, aditivos para alimentos, bebidas, embalagens, saneantes e demais produtos que interessem à saúde pública, sem registro, licença e autorizações do órgão sanitário competente ou contrariando as normas legais pertinentes:

IV - extrair, produzir, fabricar, transformar, preparar, manipular, purificar, fracionar, embalar ou reembalar, importar, exportar, armazenar, expedir, transportar, comprar, vender, ceder ou usar alimentos, produtos alimentícios, medicamentos, drogas, insumos farmacêuticos, produtos dietéticos, de higiene, cos- 
méticos, correlatos, embalagens, saneantes, utensílios e aparelhos que interessem à saúde pública ou individual, sem registro, licença, ou autorizações do órgão sanitário competente ou contrariando o disposto na legislação sanitária pertinente:

Art. 14. As penalidades previstas nesta Lei serão aplicadas pelas autoridades sanitárias competentes do Ministério da Saúde, dos Estados, do Distrito Federal e dos Territórios, conforme as atribuições que Ihes sejam conferidas pelas legislações respectivas ou por delegação de competência através de convênios". (grifo nosso)

Como pode ser observado, o legislador considerou infração sanitária a instalação de indústrias de alimentos e a comercialização de produtos sem registro no órgão competente e atribuiu às autoridades sanitárias do Ministério da Saúde e dos estados e municípios a aplicação das penalidades. Mesmo que o "órgão sanitário competente" citado nos itens I e IV do artigo 10 fosse o Ministério da Agricultura, não seria incoerente e inadequado que a penalidade fosse aplicada pela autoridade do Ministério da Saúde? Tal posição não feriria o princípio da razoabilidade? Por que o legislador estabeleceria penalidades outras já que o RIISPOA (Regulamento a Lei n. 1.283/50) já as havia estabelecido para a mesma infração, se não houvesse intenção de revogá-las?

Em 1989, entretanto, foi publicada a Lei n. 7.889, que estabeleceu a competência dos Estados e Municípios em seu art. 10:

"A prévia inspeção sanitária e industrial dos produtos de origem animal, de que trata a Lei n. 1.283, de 18 de dezembro de 1950, é da competência da União, dos Estados, do Distrito Federal e dos Municípios, nos termos do art. 23, inciso II, da Constituição."

O dispositivo, ao tentar resgatar a Lei n. 1.283, de 1950, traz novamente ao mundo jurídico a competência dos órgãos da Agricultura para a fiscalização dos produtos, a qual já deveria estar revogada desde a edição do Decreto-Lei n. 986/69 por contrariar seu texto. Ele divide a competência para a inspeção entre os entes federados e dá ao nível federal a inspeção dos estabelecimentos exportadores e de comércio interestadual, ao nível estadual aqueles de comércio intermunicipal e ao órgão municipal as empresas que se restringem a comercializar dentro do município. Mas, sempre os responsáveis são ligados a órgãos da agricultura, exceto para os estabelecimentos varejistas, como já dito anteriormente.

Um ponto positivo a ressaltar da edição da Lei $n$. $7.889 / 89$ foi que os abatedouros municipais - antes inviabilizados quando da edição da Lei n. 5.760/71, apelidada de lei da federalização da inspeção e hoje expressamente revogada, puderam novamente entrar em funcionamento devido à edição de normas específicas Estaduais e do Distrito Federal, mais brandas e adequadas às realidades locais das cidades e permitindo um meIhor combate às carnes clandestinas. Diz a Lei n. 5.760/71: 
“Art. 1É da competência da União, como norma geral de defesa e proteção da saúde, nos termos do art. $8^{\circ}$ item XVII, alíneas a e $c$ da Constituição, a prévia fiscalização sob o ponto de vista industrial e sanitário, inclusive quanto a comércio municipal ou intermunicipal, dos produtos de origem animal, de que trata a Lei n. 1.283, de 18 de dezembro de 1950". (grifo nosso)

A "lei da federalização da inspeção" obrigou todos os estabelecimentos brasileiros a obedecerem aos dispositivos do regulamento da Lei n. 1.283/50, o RIISPOA (Regulamento da Inspeção Industrial e Sanitária dos Produtos de Origem Animal - Decreto n. 30.691/52), o qual fazia exigências equivalentes a abatedouros tipo exportação e inalcançáveis pelos pequenos estabelecimentos.

Com as alterações da Lei n. $1.283 / 50$ pela Lei $n$. $7.889 / 89$, foi tacitamente considerada a sua adequação e a do seu regulamento, o RIISPOA, à nova ordem constitucional, aceitando-os como recepcionados e até hoje em vigor, pois a Lei n. 7.889, por ser de 1989 é posterior ao Decreto-lei $n$. $986 / 69$, revogando-a, portanto, no que the for contrária. A alteração proposta pela lei tenta resolver o conflito criado desde a edição do Decretolei n. 986/69 definindo um limite à atuação da Agricultura, ou seja, esta atuando sobre as indústrias e entrepostos e a saúde pública ficando com o controle dos estabelecimentos comerciais, atacadistas e varejistas.

Tem sido, todavia, esquecida ou ignorada, propositadamente ou não, a observação das alterações do texto constitucional relativas à criação do Sistema Único de Saúde - SUS - e de suas competências.

Ainda vale destacar, que a Lei $n$. $7.889 / 89$ baseia-se no parágrafo único do artigo 62 da Constituição Federal, - conforme o disposto em seu artigo $1^{\circ}-$, o qual estabelece ser competência comum à União, aos Estados, ao Distrito Federal e aos Municípios: "cuidar da saúde e assistência pública, da proteção e garantia das pessoas portadoras de deficiência...". Tais competências, histórica e constitucionalmente, são atribuições dos órgãos de saúde pública e de previdência. ${ }^{(8)}$

Claro que o intuito primeiro de se citar o art. 62 da Constituição foi respaldar a determinação da lei em descentralizar os serviços de inspeção para os Estados e Municípios, os quais, antes da nova ordem constitucional, eram atribuição somente do nível federal — ou seja, do Ministério da Agricultura - desde a expedição da Lei n. 5.760/71. Porém, podese inferir que o legislador tentou ainda em vão enquadrar a inspeção de alimentos pela Agricultura em algum dispositivo da nova Constituição, depois de sua promulgação em 1988, quando estabeleceu a instituição do Sistema Único de Saúde e de suas atribuições.

(8) A atribuição de assistência à saúde era atribuida ao órgão de Previdência e somente tinha acesso à assistência hospitalar o trabalhador com carteira assinada. Ao Ministério da Saúde cabiam as ações de prevenção, principalmente as de vacinação e de combate a vetores transmissores de doenças. 
As inspeções e fiscalizações realizadas pelos órgãos da agricultura, além de não possuírem fundamento na Constituição, vão de encontro ao seu texto que, no artigo 196, estabelece que as ações de saúde "integram uma rede regionalizada e hierarquizada e constituem um sistema único". E que ainda, no artigo 200, elenca as competências deste sistema, o Sistema Único de Saúde.

Hélio Dias (2002) concorda que a legislação específica da agricultura não deveria estar em vigor quando afirma que:

"na prática, porém, os produtos cárneos, embutidos, enlatados, leite, seus derivados e demais, de origem animal, continuam sob controle do Ministério da Agricultura, a teor da legislação especifica, cuja recepção é discutivel, em face das disposições constitucionais que atribuem ao Sistema Único de Saúde a competência para o controle dos alimentos em geral, inclusive bebidas e água para consumo humano." (grifo nosso)

O autor, em parecer feito em 1976, portanto antes na vigência da constituição anterior, já alegava que a Lei $n .1 .283 / 50$ havia sido revogada pelo Decreto-lei n. 986/69:

"uma vez revogada a lei, não pode ter revigorada sua vigência pela posterior como é o caso da Lei n. 1.283, de 18 de dezembro de 1950, que, revogada pelo Decreto-lei n. 986, de 21 de outubro de 1969, não poderia ser revigorada pela Lei n. $\mathbf{5 . 7 6 0}$, de 3 de dezembro de 1971."

Convém lembrar que a Lei n. 5.760 é a lei da federalização da inspeção, citada anteriormente e que foi expressamente substituída e revogada pela Lei n. 7.889/89.

O art. 200 da Carta Magna brasileira dá ao SUS, nos termos da Lei, dentre outras, as seguintes competências:

I - controlar e fiscalizar procedimentos, produtos e substâncias de interesse para a saúde e participar da produção de medicamentos, equipamentos, imunobiológicos, hemoderivados e outros insumos;

II - executar as ações de vigilância sanitária e epidemiológica, bem como as de saúde do trabalhador;

III - ordenar a formação de recursos humanos na área de saúde;

IV - participar da formulação da política e da execução das ações de saneamento básico;

$\mathrm{V}$ - incrementar em sua área de atuação o desenvolvimento científico e tecnológico;

$\mathrm{VI}$ - fiscalizar e inspecionar alimentos, compreendido o controle de seu teor nutricional, bem como bebidas e águas para consumo humano;

VII - participar do controle e fiscalização da produção, transporte, guarda e utilização de substâncias e produtos psicoativos, tóxicos e radioativos;

VIII - colaborar na proteção do meio ambiente, nele compreendido o do trabalho. 
A Lei a que se refere o artigo acima reproduzido é a Lei Orgânica da Saúde - LOS, Lei n. 8.080 de 19 de setembro de 1990. Importantíssimo ressaltar que a LOS é mais nova que a 7.889 (de 1989); portanto, aquela revoga esta no que lhe for contrária e, apesar de não versarem sobre o mesmo assunto, a Lei Orgânica trata da competência tendo por finalidade regulamentar artigo da Constituição Federal, ressalte-se - contrariado por dispositivos da Lei n. 7.889 - que dá claramente ao SUS a competência para a fiscalização de alimentos.

Diz a LOS, em seu art. 6º, que estão incluídas no campo de atuação do Sistema Único de Saúde a execução das ações de Vigilância Sanitária - item I, alínea a - o "controle e a fiscalização de serviços, produtos e substâncias de interesse para a saúde" - item VII —, e ainda "a fiscalização e a inspeção de alimentos, água e bebidas para consumo humano" item VIII.

O mesmo artigo, em seu $\S 1^{\circ}$, define como Vigilância Sanitária:

"um conjunto de ações capaz de eliminar, diminuir ou prevenir riscos à saúde e de intervir nos problemas sanitários decorrentes do meio ambiente, da produção e circulação de bens e da prestação de serviços de interesse da saúde, abrangendo:

1 - o controle de bens de consumo que, direta ou indiretamente, se relacionem com a saúde, compreendidas todas as etapas e processos, da produção ao consumo; e (...)." (grifo nosso)

A Constituição Federal, naqueles casos em que o constituinte pretendeu dividir as atribuições do SUS com outros setores, estabelece termos como os que podemos exemplificar no caso da fiscalização do meio ambiente, atribuindo ao SUS a competência de "colaborar na proteção do meio ambiente, ..." (art. 200, VII). E ainda como ocorre com os produtos psicoativos, para os quais estabelece a competência do SUS para "participar do controle e fiscalização... de substâncias e produtos psicoativos..." (art. 200, VII). Tais atividades também são de competência da polícia federal e das polícias judiciárias.

Em outras palavras, se o Poder Constituinte tivesse desejado que o SUS dividisse competência para fiscalizar alimentos e para desenvolver ações de Vigilância Sanitária, teria usado termos como "colaborar com" ou "participar do" controle e da fiscalização e inspeção de alimentos, bebidas e águas para consumo humano. Fato que não ocorreu.

Um argumento em favor da agricultura ainda seria a alegação que o Ministério da Agricultura, bem como os órgãos estaduais e municipais de agricultura, poderiam fazer parte do SUS e, deste modo, continuar atuando na fiscalização de alimentos. Tal argumento é facilmente desmerecido quando se lê o art. 9 da Lei n. 8.080/90 que estabelece: 
"A direção do Sistema Único de Saúde - SUS é única, de acordo com o inciso I do art. 198 da Constituição Federal, sendo exercida em cada esfera de governo pelos seguintes órgãos:

I - no âmbito da União, pelo Ministério da Saúde;

II - no âmbito dos Estados e do Distrito Federal, pela respectiva Secretaria de Saúde ou órgão equivalente; $e$

III - no âmbito dos Municípios, pela respectiva Secretaria de Saúde ou órgão equivalente."

Bom lembrar que a expressão "ou órgão equivalente" corresponde aos casos onde o ente federativo não possua secretaria de saúde específica ou com esta nomenclatura.

Apesar de o artigo tratar de direção e não de competências, não há como o órgão da agricultura, o qual possui direção e diretrizes próprias, no que se referir à fiscalização de alimentos, ficar subordinado aos gestores do Sistema Único de Saúde e ainda permanecerem expedindo normas com as mesmas finalidades.

A Lei n. 8.080/90 estabelece ainda que compete à direção nacional do SUS - ou seja, Ministério da Saúde - "controlar e fiscalizar procedimentos, produtos e substâncias de interesse à saúde" (art. 16, XII) e aos estados e municípios, no âmbito do Sistema Único de Saúde, executar as ações de vigilância sanitária (arts. 17, IV, c e 18, IV, b).

Reforçando o já exposto acima, podemos ainda citar a Lei n. 9.782, de 26 de janeiro de 1999, a qual cria a Agência Nacional de Vigilância Sanitária - ANVISA - e define o Sistema Nacional de Vigilância Sanitária. Esta estabelece, em seu artigo 2ㅇ, que "compete à União, no âmbito do Sistema Nacional de Vigilância Sanitária: I. Normatizar, controlar e fiscalizar produtos, substâncias e serviços de interesse à saúde; (...)".

O artigo 6 da mesma Lei estabelece como finalidade da ANVISA:

"promover a proteção da saúde da população, por intermédio do controle sanitário da produção e da comercialização de produtos ... submetidos à vigilância sanitária, inclusive dos ambientes, dos processos, dos insumos e das tecnologias a eles relacionados."

O inciso II do $\S 1^{\circ}$ do art. $8^{\circ}$ da Lei $n$. 9.782/99, ainda considera os "alimentos, inclusive bebidas, águas envasadas" como bens e produtos submetidos ao controle e fiscalização pela ANVISA, entidade do Sistema Nacional de Vigilância Sanitária, vinculado ao Ministério da Saúde.

O § 3 do art. 41 da Lei n. 9.782/99, alterado pela Medida Provisória n. 2.190-34, de 23.8.2001, contribui ainda mais para o conflito pois obriga as indústrias de alimentos a possuírem autorização de funcionamento junto à Agência Nacional de Vigilância Sanitária: 
"§ $3^{\circ}$ As empresas sujeitas ao Decreto-lei n. 986, de 1969, ficam, também, obrigadas a cumprir o art. $2^{\circ}$ da Lei $n$. 6.360 , de 1976 , no que se refere à autorização de funcionamento pelo Ministério da Saúde e ao licenciamento pelos órgãos sanitários das Unidades Federativas em que se localizem." (NR)

Com isto, os estabelecimentos industriais de origem animal, se se considerar em vigor a Lei n. 7.889/89, devem possuir, simultaneamente, registro junto ao Ministério da Agricultura e Autorização de Funcionamento junto à ANVISA, configurando uma clara duplicidade de atuações do Estado para um mesmo fim, implicando inclusive em duplicidade de cobrança de taxas, o que também é inconstitucional, por se caracterizar bitributação. Por isso, seria coerente a aplicação do princípio da revogação da lei anterior pela nova, considerando que Medida Provisória tem status de lei ordinária e, portanto, revoga o dispositivo legal anterior e contrário.

Vale destacar aqui que com, a edição da Resolução ANVISA n. 23/00, foi dispensada da obrigatoriedade de registro a maioria dos alimentos, permanecendo sob a obrigação de registrar somente aqueles que possuam risco elevado, características especiais como os dietéticos, os com propriedades de saúde, a água mineral, o palmito em conserva, dentre outros.

Interessante ressaltar que, da lista dos produtos com registro obrigatório constante do anexo II da Resolução, constam os produtos de origem animal "de competência do Ministério da Saúde". Com a resolução, a própria ANVISA tende a admitir a existência de produtos de origem animal que não são de sua competência, possibilitando a inferência de que esta não tem interesse em assumir o controle de tais produtos.

Mais um dispositivo recente que reforça a competência legal da saúde para atuar em fiscalização de alimentos pode ser encontrado na recente Lei n. 10.683/03, a qual reestrutura o Governo Federal. Esta lei dá as atribuições dos diversos setores, órgãos e Ministérios formadores da estrutura administrativa da União. buições:

Ao Ministério da Agricultura (art. 27, I, g) outorga, dentre outras atri-

a classificação e inspeção de produtos e derivados animais e vegetais, inclusive em ações de apoio às atividades exercidas pelo Ministério da Fazenda, relativamente ao comércio exterior;

Não usa, no entanto, a palavra alimento em momento algum, permitindo a conclusão, portanto, que os produtos citados podem ou não ser alimentícios, tratando-se provavelmente de grãos, sementes, matériasprimas, produtos veterinários, rações para animais, plantas e outros insumos, produtos estes que sempre couberam originariamente aos órgãos da agricultura e suas fiscalizações.

A palavra "derivados", que poderia ser interpretada como abrangendo os produtos alimentícios numa primeira leitura, não os inclui, de acor- 
do com o art. 19 do RIISPOA, que dispõe que "A simples designação "produto", "subproduto", "mercadoria", ou "gênero" significa, para efeito do presente Regulamento, que se trata de "produto de origem animal ou suas matérias-primas"'. Como pode ser percebido, dos conceitos que são incluídos na designação de produto de origem animal não faz parte a palavra "derivados". Ademais, o Decreto-lei n. 986/69, última norma, com status de lei, publicada no Brasil e que traz definições relativas a alimentos, define diferentemente alimento in natura de produto alimentício e de matéria-prima alimentar.

"Art. $2^{\circ}$ Para os efeitos deste Decreto-lei considera-se:

I -Alimento: toda substância ou mistura de substâncias, no estado sólido, líquido, pastoso ou qualquer outra forma adequada, destinadas a fornecer ao organismo humano os elementos normais à sua formação, manutenção e desenvolvimento;

II - Matéria-prima alimentar: toda substância de origem vegetal ou animal, em estado bruto, que para ser utilizada como alimento precise sofrer tratamento e/ou transformação de natureza física, química ou biológica;

III - Alimento in natura: todo alimento de origem vegetal ou animal, para cujo consumo imediato se exija, apenas, a remoção da parte não comestivel e os tratamentos indicados para a sua perfeita higienização e conservação;

$X$ - Produto alimentício: todo alimento derivado de matéria-prima alimentar ou de alimento in natura, adicionado, ou não, de outras substâncias permitidas, obtido por processo tecnológico adequado;"

Pode-se concluir, da leitura dos conceitos, que a carne, o leite, o mel e os ovos se enquadram nos conceitos de alimento in natura ou de matéria-prima alimentar, não podendo, de forma alguma, ser classificados como produtos alimentícios ou mesmo como derivados e, conseqüentemente, estão fora do âmbito de competência do Ministério da Agricultura dado pela recente Lei $n$. 10.683/03.

Para o Ministério da Saúde, entretanto, a lei - no mesmo dispositivo (art. 27, XX, g) - é clara ao atribuir ao Ministério da Saúde a competência de fazer "vigilância de saúde, especialmente quanto às drogas, medicamentos e alimentos". Por vigilância da saúde entendem-se as vigilâncias sanitária e epidemiológica, ambas de competência do Sistema Único de Saúde. Como já exposto anteriormente, a definição de Vigilância Sanitária, dada pela Lei $\mathrm{n}$. 8.080/90 inclui a fiscalização de alimentos da produção ao consumo.

Em pesquisa jurisprudencial realizada - junto aos Tribunais Superiores e aos Tribunais Regionais Federais, por meio da internet - mesmo tendo sido encontrado um único processo judicial relativo ao assunto, ele ilustra com propriedade a existência do conflito de competência e vem a confirmar a superioridade do Decreto-lei n. 986/69 sobre a Lei $n$. 1.283/ 50. O processo trata de apelação cível interposta pela União Federal, em ação cautelar, contra sentença que permitiu à indústria de doces que utilizava leite na preparação de alimentos a comercialização de seus produtos sem a inscrição na Divisão de Inspeção de Produtos de Origem Animal - DIPOA. 
Foi exigido da empresa, pelo Ministério da Agricultura, com fundamento na Lei n. 1.283/50, que fosse providenciado seu registro junto ao DIPOA, apesar de já possuir registro de seus produtos junto ao Ministério da Saúde.

O acórdão nega, por unanimidade, o provimento à apelação de acordo com o voto do relator, o qual, tendo por base a Lei Orgânica de Saúde, considera inadmissivel a duplicidade de registros.

\begin{abstract}
"a empresa já se encontra sujeita ao registro perante o Ministério da Saúde nos termos do artigo 3ํ do Decreto-lei n. 986/69 ("Todo alimento somente será exposto ao consumo ou entregue à venda depois de registrado no órgão competente do Ministério da Saúde") (fl. 50).

Por sua vez, o artigo $6^{\circ}$, inciso VIII, da Lei n. 8.080/90 estabelece que estão incluidas no campo de atuação do Sistema Único de Saúde - SUS a fiscalização e a inspeção de alimentos, água e bebidas para consumo humano.

Assim sendo, é inadmissivel, sem norma legal expressa, exigir novo registro perante outro órgão da Administração Federal (Carta Magna, art. 5ํ, II)." (grifo nosso)
\end{abstract}

Diante do exposto, é pertinente citar novamente Hélio Dias (2002) quando afirma com propriedade que:

"urge, portanto, que se ponha fim a esses desencontros finalisticos das duas Pastas, compatibilizando-se as normas infraconstitucionais, eliminando-se de vez os conflitos existentes, evitando-se perplexidades que o Direito repele."

\title{
CONCLUSÃO
}

Depois da avaliação de toda a legislação em vigor relacionada às competências para a fiscalização dos alimentos de origem animal, aplicando-se os conhecimentos doutrinários, inclusive os relativos ao conflito de leis no tempo, pode-se concluir que, apesar de não ter havido, em momento nenhum, a revogação expressa da lei que dá competência aos órgãos da Agricultura, há fortes indícios que estes, desde a edição do Decreto-lei n. 986/69, não possuem respaldo legal para exercer suas atribuições.

Por ferị o art. 200 da Constituição Federal, o qual dá tal atribuição ao Sistema Único de Saúde, a Lei $n$. $7.889 / 89$ possui vícios de inconstitucionalidade e, portanto, em tese não pode revogar o decreto-lei, apesar de ser mais recente que ele. A Lei de 1989 é o único diploma legal expedido após o novo texto constitucional e que seria capaz de resgatar a competência da Agricultura para a inspeção de alimentos.

Apesar de nunca ter sofrido ação de inconstitucionalidade perante o Supremo Tribunal Federal ou ter tido sua inconstitucionalidade argüida em ação judicial - considerando pesquisa jurisprudencial realizada neste 
estudo - há argumentos para se alegar seu conflito com a Carta Magna, e urge este questionamento por via de ação direta, por um dos atores com legitimidade ativa para impetrá-la.

Apesar de ter concluído pela existência do conflito de atribuições entre órgãos do Poder Executivo, a pesquisa jurisprudencial realizada no curso de elaboração deste trabalho não revelou a existência de questionamentos judiciais em número suficiente a levar a conclusão de que os embates estejam chegando ao Poder Judiciário, ou seja, que o setor empresarial tenha se sentido prejudicado a ponto de recorrer a outro poder do Estado para buscar a resolução do conflito.

Outra conclusão possível é a de que, apesar de ter consciência do problema, o poder público, representado pelos órgãos fiscalizadores, tanto relacionados à saúde pública quanto os ligados à Agricultura, continuam a ignorar os óbices jurídicos dividindo atribuições que podem não ser concorrentes. Interessante citar Bandeira de Mello (2003) quando afirma que o Poder Executivo tem a tendência de se sobrepor às leis: "o Executivo, no Brasil, abomina a legalidade e tem o costumeiro hábito de afrontá-la, sem ser nisto coartado, como devido".

Diante das possiveis ilegalidades e da inconstitucionalidade verificadas após o estudo detalhado da legislação em vigor, as seguintes propostas podem ser apresentadas visando à correção definitiva do problema:

- O Departamento de Inspeção de Produtos de Origem Animal, ligado à Secretaria de Defesa Agropecuária do Ministério da Agricultura, com toda sua estrutura e recursos, poderia, ser transferido para a Agência Nacional de Vigilância Sanitária - com conseqüente alteração de denominação - bem como os seus servidores concursados redistribuídos para a autarquia. Tal medida, além de corrigir as incompatibilidades jurídicas, permitiria, pela inclusão do órgão no SUS, a possibilidade de sofrer controle social, uma das diretrizes deste sistema. A atuação da Agricultura, no caso dos alimentos de origem animal, deve se limitar ao controle sanitário dos animais vivos (denominado defesa sanitária animal, competência originária do Ministério e secretarias estaduais municipais de agricultura) até o momento em que chegam ao abatedouro.

- O RIISPOA, que continua recepcionado por não conter dispositivos conflitantes com o texto constitucional, deverá ser aplicado pelos órgãos e pelos servidores ligados ao Sistema Único de Saúde;

- Toda a normatização infraconstitucional — ou seja, leis, regulamentos, portarias e resoluções - deverá ser revista e reorganizada de modo a se tornar compatível com as determinações constitucionais.

- Outra alternativa, caso não se pretenda executar as alterações de ordem administrativa anteriores, seria a apresentação de proposta de emenda constitucional que inclua termos como "Participar do" ou "colaborar com" no inciso VI do artigo 200 da Constituição Federal, o qual dá 
atribuição ao SUS para a inspeção de alimentos, bem como que inclua, no capítulo referente à política agrícola, a competência para a inspeção dos alimentos de origem animal. Neste caso, haveria necessidade de as normas infraconstitucionais fazerem a divisão clara dos limites de atribuições mantendo os animais vivos, até o momento pós-abate, sob a competência da Agricultura e, a partir daí, atribuir aos órgãos de saúde pública o controle das matérias-primas e dos produtos alimentícios destinados ao consumo humano.

\section{REFERÊNCIAS BIBLIOGRÁFICAS E LEGISLATIVAS}

BASTOS, C. R., MARTINS, I. G. "Comentários à Constituição do Brasil". São Paulo: Saraiva, 1990.

DIAS, Hélio Pereira. "Direitos e obrigações em saúde". Brasília: Agência Nacional de Vigilância Sanitária, 2002, 387 p.

Parecer n. 4.009/76, de 15 de janeiro de 1976, dirigido ao Presidente da República pelo Ministro da Saúde. "Direitos e obrigações em saúde". Brasília: ANVISA, 2002, p. 217.

MEIRELLES, H. L. "Direito administrativo brasileiro", 24a ed., São Paulo: Malheiros Ed. Editores, 1999, 749 p.

MELLO, C. A. Bandeira de. "Curso de direito administrativo", 15 $5^{\text {a }}$ ed., São Paulo: Malheiros Ed., 2003, 922 p.

MIRANDA, J. "Manual de direito constitucional", $2^{\text {a }}$ ed. rev. e atual., Coimbra: Coimbra Ed., 1993.

ROZENFELD, Suely; COSTA, Ediná Alves. "Constituição da Vigilância Sanitária no Brasil. Fundamentos da Vigilância Sanitária". Rio de Janeiro: Editora Fiocruz, 2000, pp. 15-40.

SILVA, José Afonso. "Curso de direito constitucional positivo", 22ª ed., São Paulo: Malheiros Ed., 2003, 878 p.

\section{Legislação}

BRASIL. Agência Nacional de Vigilância Sanitária. Resolução ANVISA n. 23, de 15 de março de 2000. Diário Oficial, Brasília, Diário Oficial de 16 de março de 2000 - Seção 1. Dispõe sobre o Manual de Procedimentos Básicos para Registro e Dispensa da Obrigatoriedade de Registro de Produtos Pertinentes à Área de Alimento.

Constituição da República Federativa, promulgada em 5 de outubro de 1988. Brasília, Senado Federal. 1988. 
Decreto n. 30.691, de 29 de março de 1952. Coleção de Leis do Brasil, Rio de Janeiro, 7 de julho de 1952. Aprova o novo Regulamento da Inspeção Industrial e Sanitária de Produtos de Origem Animal. Disponível em: <http://www.agricultura.gov.br/sda/dipoa/reginterno.htm>. Acesso em: 27 out. 2003.

Decreto-lei n. 4.657 , de 4 de setembro de 1942. Coleção de Leis do Brasil, Rio de Janeiro, 9 de setembro de 1942. Lei de Introdução ao Código Civil Brasileiro. Disponível em: <https://www.presidencia. gov.br/ legisla.htm>. Acesso em: 27 out. 2003.

Decreto-lei n. 986, de 21 de outubro de 1969. Diário Oficial, Brasília, de 21 de outubro de 1969. Seção I pt. I, v. 107, n. 202, pp. 8.935-8. Institui normas básicas sobre alimentos.

Lei n. 8.112, de 11 de dezembro de 1990. Brasília, Diário Oficial, 12 de dezembro de 1990, Seção I, p. 023935. Dispõe sobre o Regime Jurídico dos Servidores Públicos Civis da União, das autarquias e das fundações públicas federais.

Lei n. 1.283, de 18 de dezembro de 1950. Diário Oficial dos Estados Unidos do Brasil. Rio de Janeiro, 19 de dezembro de 1950. Seção 1, p. 18161. Dispõe sobre a inspeção industrial e sanitária dos produtos de origem animal dá outras providências.

Lei n. 10.683, de 28 de maio de 2003. Diário Oficial, Brasília, de 19 de maio de 2003. Dispõe sobre a organização da Presidência da República e dos Ministérios, e dá outras providências. Disponível em: <http://www.presidencia.gov.br/legislacao>. Acesso em: 27 out. 2003.

Lei n. 9.782, de 26 de janeiro de 1999. Diário Oficial, Brasília, 27 de janeiro de 1999, Seção 1, v. 137, n. 18, p. 1. Dispõe sobre o Sistema Nacional de Vigilância Sanitária, cria a Agência Nacional de Vigilância Sanitária e dá outras providências.

Lei n. 5.760, de 3 de dezembro de 1971. Diário Oficial, Brasília, 7 de dezembro de 1971 Seção 1, p. 010003. Dispõe sobre a inspeção sanitária e industrial dos produtos de origem animal e dá outras providências.

Lei n. 6.437, de 20 de agosto de 1977. Diário Oficial, Brasília, 24 de agosto de 1977. Seção I, v. 115, n. 162, p. 11145. Configura infrações à legislação sanitária federal e estabelece as sanções respectivas.

Lei n. 7.889, de 23 de novembro de 1989. Diário Oficial, Brasília, 24 de novembro de 1989. Seção 1, p. 21529. Dispõe sobre inspeção sanitária e industrial dos produtos de origem animal, e dá outras providências.

Lei n. 8.080, de 19 de setembro de 1990. Diário Oficial, Brasília, 20 de setembro de 1990. Seção I, pt. I, p. 18055-9. Institui o Sistema Único de Saúde. 
Medida Provisória n. 1.791, de 30 de dezembro de 1998. Define o Sistema Nacional de Vigilância Sanitária, cria a Agência Nacional de Vigilância Sanitária, e dá outras providências. Disponível em: <http:// wwwt.senado.gov.br/servlets/NJUR. Filtro?tipo=MPV\&secao=NJUILEG BRAS\&numLei $=001791 \&$ data $=19981230 \&$ pathServer $=w w w 1 /$ netacgi/nphbrs.exe\&seq $=000>$. Acesso em: 8 out. 2003.

Medida Provisória n. 2.048-26, de 29 de junho de 2000. Diário Oficial, Brasília, 30 de junho de 2000. Dispõe sobre a criação, reestruturação e organização de carreiras, cargos e funções comissionadas técnicas no âmbito da Administração Pública Federal direta, autárquica e funcional, dá nova redação ao art. 57 da Lei n. 4.878, de 3 de dezembro de 1965, que dispõe sobre o regime jurídico peculiar aos funcionários policiais civis da União e do Distrito Federal, e dá outras providências. Disponivel em: <https://www.presidencia.gov.br/legisla.htm>. Acesso em: $1 \stackrel{0}{0}$ out. 2003.

Medida Provisória n. 2.190-34, de 23 de agosto de 2001. Diário Oficial, Brasília, 29 de junho de 2001. Altera dispositivos das Leis n. 9.782, de 26 de janeiro de 1999, que define o Sistema Nacional de Vigilância Sanitária e cria a Agência Nacional de Vigilância Sanitária, e n. 6.437, de 20 de agosto de 1977, que configura infrações à legislação sanitária federal e estabelece as sanções respectivas, e dá outras providências.

Ministério da Agricultura, Pecuária e Abastecimento. Regimento Interno do Departamento de Produtos de Origem Animal. Disponível em: <http://www.agricultura.gov.br/sda/dipoa/reginterno.htm>. Acesso em: 27 out. 2003.

Ministério da Agricultura. Portaria n. 368 , de 4 de setembro de 1997. Diário Oficial, Brasília, 8 de setembro de 1997. N. 172, Seção 1. Aprova o Regulamento Técnico sobre as condições Higiênico-Sanitárias e de Boas Práticas de Fabricação para Estabelecimentos Elaboradores/ Industrializadores de Alimentos.

Ministério da Saúde. Portaria n. 326, de 30 de julho de 1997. Diário Oficial, Brasília, 1ำ de agosto de 1997. Seção I, p. 21005-12. Aprova o Regulamento Técnico: condições Higiênico-Sanitárias e de Boas Práticas de Fabricação para Estabelecimentos Produtores/Industrializadores de Alimentos.

Supremo Tribunal Federal. Ação Direta de Inconstitucionalidade n. 2.310, de 29 de agosto de 2000. Disponível Disponivel em: http:/ /gemini.stf.gov.br/cgi-bin/nph-brs?d=ADIN\&s1=2310\&u=http://http:// www.stf.gov.br//Jurisprudencia/Jurisp.asp\&Sect1 $=\mid M A G E \&$ Sect2 $=$ THESOFF\&Sect $3=P L U R O N \& S e c t 6=A D I N N \& p=1 \& r=1 \& f=G \& n=\& I=20$. Acesso em: 01 nov. 2003. 
Supremo Tribunal Federal. Súmula n. 473, de 3 de outubro de 1969. A administração pode anular seus próprios atos, quando eivados de vícios que os tornam ilegais, porque deles não se originam direitos; ou revogá-los, por motivo de conveniência ou oportunidade, respeitados os direitos adquiridos, e ressalvada, em todos os casos, a apreciação judicial. Disponivel em: <http://gemini.stf.gov.br/netahtml/jurisp.html>. Acesso em: 1 으. 2003.

Tribunal Regional Federal/MG. Apelação Cível $\mathrm{n}$. 1997.01.00.042330-8, de 9 de outubro de 2003. Terceira turma suplementar. Relator: Leão Aparecido Alves. Disponível em: <http:// arquivo.trf1.gov.br/default.asp?processoX $=199701000423308>$. Acesso em: $1^{\circ}$ out. 2003. 